\title{
Mechanical Allodynia Caused by Intraplantar Injection of P2X Receptor Agonist in Rats: Involvement of Heteromeric P2X $2 / 3$ Receptor Signaling in Capsaicin-Insensitive Primary Afferent Neurons
}

\author{
Makoto Tsuda, ${ }^{1}$ Schuichi Koizumi, ${ }^{1}$ Aya Kita, ${ }^{1}$ Yukari Shigemoto, ${ }^{1}$ Shinya Ueno, ${ }^{2}$ and Kazuhide Inoue ${ }^{1,3}$ \\ 'Section of Neuropharmacology, Division of Pharmacology, National Institute of Health Sciences, 1-18-1 Kamiyoga, \\ Setagaya-ku, Tokyo 158-8501, Japan, 2Department of Pharmacology, Fukuoka University School of Medicine, \\ 7-45-1 Nanakuma, Jyonan-ku, Fukuoka 814-0180, Japan, and ${ }^{3}$ Graduate School of Pharmaceutical Sciences, \\ Kyushu University, 3-1-1 Maidashi Higashi, Fukuoka 812-8582, Japan
}

\begin{abstract}
Extracellular ATP has been known to activate sensory neurons via the ATP-gated ion channels P2X receptors, indicating that the P2X receptors may play a role in signal transduction of pain from the periphery to the spinal cord in vivo. Here, we found a novel nociceptive response induced by ATP, mechanical allodynia (hypersensitivity to innocuous mechanical stimulus). Injection of $\alpha, \beta$-methylene ATP ( $\alpha \beta$ meATP), an agonist to P2X receptor, into plantar surface in rats produced the mechanical allodynia along with previously described nocifensive behavior and thermal hyperalgesia. This allodynic response was blocked by pretreatment with the P2 receptor antagonist pyridoxalphosphate-6-azophenyl-2',4'-disulfonate. Interestingly, only the mechanical allodynia evoked by $\alpha \beta$ meATP selectively remained in neonatal capsaicin-treated adult rats that had selectively lost the capsaicin-sensitive neurons. ATP has been shown to produce two distinguishable electrophysiological responses
\end{abstract}

(inward currents with rapid and slow desensitization) in dorsal root ganglion (DRG) neurons. In the present electrophysiological experiment, the percentage of DRG neurons that responded to $\alpha \beta$ meATP with slow desensitizing inward current remained constant in capsaicin-treated rats, whereas the percentage that responded with rapid desensitizing current dramatically decreased. Taken together with our previous finding that the $\alpha \beta$ meATP-activated slow desensitizing current in DRG neurons is mediated by heteromeric $\mathrm{P} 2 \mathrm{X}_{2 / 3}\left(\mathrm{P} 2 \mathrm{X}_{2}\right.$ and $\left.\mathrm{P} 2 \mathrm{X}_{3}\right)$ receptors, it is hypothesized that activation of heteromeric $\mathrm{P} 2 \mathrm{X}_{2 / 3}$ receptors in peripheral terminals of capsaicin-insensitive primary afferent fibers leads to the induction of mechanical allodynia.

Key words: $\alpha, \beta$-methylene ATP; P2X receptors; mechanical allodynia; dorsal root ganglia; primary afferent fibers; capsaicin sensitivity
In light of recent accumulating evidence that extracellular ATP excites primary sensory neurons via ATP-gated cation channels ( $\mathrm{P} 2 \mathrm{X}$ receptors), it has been postulated that the $\mathrm{P} 2 \mathrm{X}$ receptors in sensory neurons play a role in signal transduction of pain from the periphery to the spinal cord in vivo (for review, see Burnstock and Wood, 1996; Ralevic and Burnstock, 1998). This proposal has been strongly supported by the intriguing findings that mRNA of the $\mathrm{P} 2 \mathrm{X}_{3}$ receptor, which is one of seven cloned $\mathrm{P} 2 \mathrm{X}$ receptor subtypes $\left(\mathrm{P} 2 \mathrm{X}_{1}-\mathrm{P} 2 \mathrm{X}_{7}\right)$ (for review, see Ralevic and Burnstock, 1998), is expressed selectively in the trigeminal ganglion (TG) and dorsal root ganglion (DRG) neurons (Chen et al., 1995; Lewis et al., 1995). To date, in addition to P2X $\mathrm{X}_{3}$, mRNAs of the $\mathrm{P} 2 \mathrm{X}_{1,2,4-6}$ receptors have also been shown in primary sensory neurons (Collo et al., 1996). Interestingly, the distributions of some of these P2X receptor subtypes show different patterns (Xiang et al., 1998; Ueno et al., 1999), suggesting that there are several types of cells that express different $\mathrm{P} 2 \mathrm{X}$ receptor subtypes. This idea is substantiated by recent electrophysiological findings by Cook et al. (1997) showing that an inward current evoked by ATP or its analog $\alpha, \beta$-methylene ATP $(\alpha \beta$ meATP) in

Received April 4, 2000; revised May 17, 2000; accepted May 24, 2000.

This work was supported by a Domestic Research Fellowship from Japan Science and Technology Corporation. We thank Prof. M. W. Salter for improving this manuscript.

Correspondence should be addressed to Dr. Kazuhide Inoue, Section of Neuropharmacology, Division of Pharmacology, National Institute of Health Sciences, 1-18-1 Kamiyoga, Setagaya-ku, Tokyo 158-8501, Japan. E-mail: inoue@nihs.go.jp. Copyright (C) 2000 Society for Neuroscience $0270-6474 / 00 / 200001-05 \$ 15.00 / 0$
TG neurons can be kinetically divided into two populations: inward currents with rapid and slow desensitization. Primary sensory neurons have been classified neurochemically and neuroanatomically into several groups. The newly cloned capsaicin receptor vanilloid receptor 1 (VR1) has been shown to express neurons that are primarily small in diameter (Caterina et al., 1997). Thus, we previously attempted to classify the two distinct types of ATP currents using the VR1 agonist capsaicin as a functional marker of DRG neurons, and obtained the intriguing evidence that the capsaicin-sensitive, small-sized DRG neurons and the capsaicin-insensitive, medium-sized DRG neurons have ATP or $\alpha \beta$ meATP-induced inward currents with rapid and slow desensitization, respectively (Ueno et al., 1999). From these findings, we have proposed that these two groups may relay distinct aspects of $\mathrm{P} 2 \mathrm{X}$ receptor-mediated pain signaling from the periph-

This article is published in The Journal of Neuroscience, Rapid Communications Section, which publishes brief, peer-reviewed papers online, not in print. Rapid Communications are posted online approximately one month earlier than they would appear if printed. They are listed in the Table of Contents of the next open issue of JNeurosci. Cite this article as: JNeurosci, 2000, 20:RC90 (1-5). The publication date is the date of posting online at www.jneurosci.org.

http://www.jneurosci.org/cgi/content/full/4404 
ery to the spinal cord in vivo. To date, however, no evidence has yet been presented.

Here, we describe a newly characterized behavioral phenotype, mechanical allodynia, caused by intraplantar injection of $\alpha \beta$ meATP in rats, in addition to previously described thermal hyperalgesia and nocifensive behavior (Bland-Ward and Humphrey, 1997; Hamilton et al., 1999). Moreover, we provide evidence that the mechanical allodynia and the previously described behaviors (thermal hyperalgesia and nocifensive behavior) are signaled by distinct $\mathrm{P} 2 \mathrm{X}$ receptors corresponding to either capsaicin-insensitive or -sensitive primary afferent fibers, respectively, using the capsaicin-sensitive neuron-destroyed rats (Jancsó et al., 1977; Nagy et al., 1983).

\section{MATERIALS AND METHODS}

Materials. $\alpha$ meATP (RBI, Natick, MA), ATP, adenosine (Sigma, St. Louis, MO), and pyridoxal-phosphate-6-azophenyl-2',4'-disulfonate (PPADS) (RBI) were dissolved in PBS. Capsaicin (Wako Pure Chemical Industries, Osaka, Japan) was dissolved in $10 \%$ ethanol, $10 \%$ Tween 80 , and $80 \%$ saline.

Animals. Male Wistar rats (190-230 gm) were used. Rats were housed at a temperature of $22 \pm 1^{\circ} \mathrm{C}$ with a $12 \mathrm{hr}$ light/dark cycle (light on from 8:30 A.M. to 8:30 P.M.) and were fed food and water ad libitum.

Neonatal capsaicin treatment. To destroy the capsaicin-sensitive neurons, neonatal Wistar rats were injected subcutaneously with capsaicin $(50 \mathrm{mg} / \mathrm{kg})$ at $2 \mathrm{~d}$ after birth. After 8-9 weeks, we used only the capsaicin-treated rats that responded with two or less wipes by application of capsaicin solution $(0.01 \%)$ to the cornea.

Behavioral experiments. Rats were injected with PBS, $\alpha \beta$ meATP, ATP, or adenosine in the plantar surface of the left hindpaw. Rats were placed in a wire mesh cage immediately after injection, and time spent in hindpaw lifting during the first 4 min was measured as an indicator of the nocifensive behavior. Noxious heat-evoked paw withdrawal response was detected by application of radiant heat to the plantar surface of the hindpaw. Rats were placed on a clear glass cylinder (diameter, $12 \mathrm{~cm}$; height, $10 \mathrm{~cm}$ ), and each hindpaw was positioned at the heat source in an apparatus (Ugo Basile, Varese, Italy). The intensity of the heat stimulus was adjusted for paw withdrawal latency of $12-15 \mathrm{sec}$ in normal animals. A cutoff time was set at $22 \mathrm{sec}$. Sensitivity to mechanical stimulus was assessed using calibrated von Frey filaments (Stoelting, Wood Dale, IL). Rats were placed in wire mesh cage and the von Frey filaments (0.4-15.1 gm) were applied to the mid-plantar surface of each hindpaw. The mechanical stimulus producing the $50 \%$ paw withdrawal threshold was determined using the up-down method (Chaplan et al., 1994). Behavioral tests using heat and mechanical stimuli were performed immediately before and at $5,15,30,60$, and 120 min after intraplantar injection of PBS, $\alpha \beta$ meATP, or ATP. The P2 receptor antagonist PPADS was injected into the plantar surface $10 \mathrm{~min}$ before $\alpha \beta$ meATP injection. The injection volume of PBS, $\alpha \beta$ meATP, ATP, or adenosine was $100 \mu \mathrm{l}$; the injection volume of PPADS was $50 \mu 1$.

Electrophysiological experiments in acute isolated rat DRG neurons. The DRGs (L4-6 segments) were removed from Wistar rats (normal and capsaicin-treated rats) and were treated in DMEM with $20 \mathrm{U} / \mathrm{ml}$ papain and $2 \mathrm{mg} / \mathrm{ml}$ collagenase type II for $1 \mathrm{hr}$ at $37^{\circ} \mathrm{C}$. At the end of this treatment, the enzyme solution was removed and the cells were then mechanically dissociated by trituration through a Pasteur pipette. Cells were plated on polystyrene dishes for physiological experiments. Recordings were made using the conventional whole-cell patch-clamp method (Hamill et al., 1981), with minor modifications as described previously (Ueno et al., 1999). Membrane potential was held at $-50 \mathrm{mV}$, and liquid-liquid junction potentials were corrected. The pipette solution contained (in mM): $\mathrm{CsCl} 140, \mathrm{MgCl}_{2} 2$, EGTA 5, and HEPES 10; $\mathrm{pH}$ was adjusted to 7.3 with $\mathrm{CsOH}$. The pipette resistances were 1-5 M $\Omega$. Series resistance (1.4-9.0 M $\Omega$ ) and cell capacitance (12-90 pF) were compensated up to $80 \%$. Currents were filtered at $300 \mathrm{~Hz}$ with an eight-pole Bessel filter (Frequency Devices, Haverhill, MA) and measured with an Axopatch 200A amplifier (Axon Instruments, Foster City, CA). Data were then sampled at $1 \mathrm{kHz}$ and stored on-line with a $486 \mathrm{PC}$ using pClamp software (Axon Instruments). Drugs were dissolved in an external solution of the following composition (in $\mathrm{mM}$ ): $\mathrm{NaCl} \mathrm{150,} \mathrm{KCl} \mathrm{5,}$ $\mathrm{CaCl}_{2} 2, \mathrm{MgCl}_{2}$, D-glucose 10 , and HEPES $10 ; \mathrm{pH}$ was adjusted to 7.4 with $\mathrm{NaOH}$.

Statistical analyses. Statistical analyses of the results from behavioral test were evaluated using the Student's $t$ test or the nonparametric Mann-Whitney $U$ test. The area under the response-time curve (AUC) for mechanical thresholds for PBS, $\alpha \beta$ meATP, ATP, or adenosine was shown by measurement of the area under the base value at 0 min $(15.1$ $\mathrm{gm})$ at $0-120 \mathrm{~min}$ after intraplantar injections. The AUC was calculated under the condition that the ordinate (gram; paw withdrawal threshold) is logarithm scale and was statistically analyzed by the Student's $t$ test or the nonparametric Mann-Whitney $U$ test. For electrophysiological data,
A.

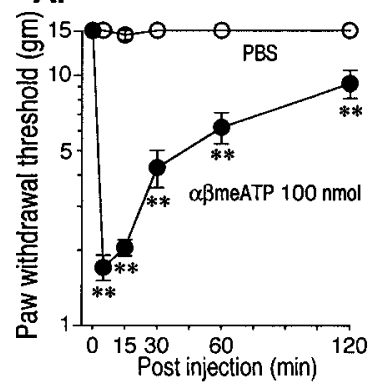

C. $\quad \alpha \beta m e A T P 100 \mathrm{nmol}$

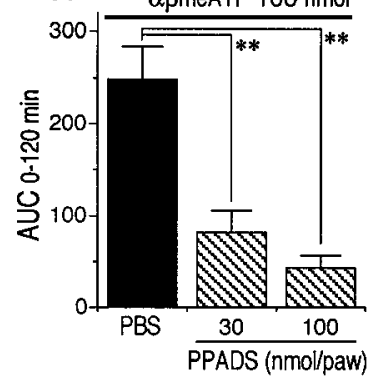

B.

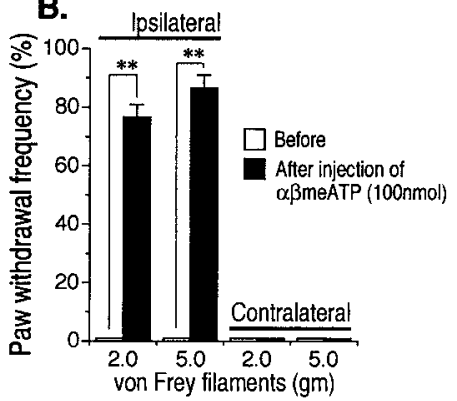

D.

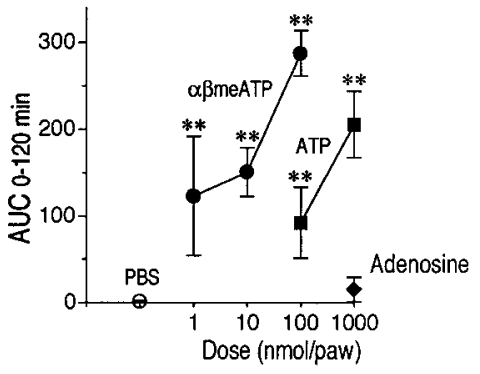

Figure 1. An injection of $\alpha \beta$ meATP or ATP into the plantar surface of the hindpaw produced mechanical allodynia that was PPADS (P2 receptor antagonist) -sensitive. $A$, Time course of the mechanical allodynia evoked by $\alpha \beta$ meATP $(100 \mathrm{nmol})$. The mean \pm SEM paw withdrawal threshold (in grams) for von Frey filaments is shown ${ }^{* *} p<0.01$ by the Mann-Whitney $U$ test, compared with PBS-injected rats). $B$, Mean \pm SEM paw withdrawal frequency to von Frey filaments $(2.0$ and $5.0 \mathrm{gm}) 5$ min after the injection of $\alpha \beta$ meATP $(100 \mathrm{nmol})\left(^{* *} p<0.01\right.$ by the Mann-Whitney $U$ test, compared with the contralateral hindpaw). $C$, Blockade of $\alpha \beta$ meATP-induced mechanical allodynia by the P2 receptor antagonist PPADS (30 and $100 \mathrm{nmol})$. The mean \pm SEM AUC [area under the base value at $0 \mathrm{~min}(15.1 \mathrm{gm})]$ at $0-120 \mathrm{~min}$ after injection of $\alpha \beta$ meATP is shown (**p $<0.01$ by the Student's $t$ test or the MannWhitney $U$ test, compared with PBS-pretreated rats). $D$, Dose-response of the mechanical allodynia evoked by $\alpha \beta$ meATP $(1-100 \mathrm{nmol})$, ATP (100 and $1000 \mathrm{nmol})$, and adenosine $(1000 \mathrm{nmol})$. The mean \pm SEM AUC at $0-120 \mathrm{~min}$ after injection is shown ${ }^{* *} p<0.01$ by the Student's $t$ test or the Mann-Whitney $U$ test, compared with PBS-injected rats). Each point and column represents the mean \pm SEM of five to seven rats.

statistical analyses of the percentage of DRG neurons and the current density were evaluated using the $\chi^{2}$ test and the Student's $t$ test, respectively.

\section{RESULTS}

\section{P2X receptor-mediated mechanical allodynia}

Intraplantar injection with $\alpha \beta$ meATP (100 nmol) dramatically decreased the paw withdrawal threshold for mechanical stimulation by von Frey filaments $(p<0.01$, significantly different from the threshold in PBS-treated rats at 5, 15 30, 60, and 120 min after $\alpha \beta$ meATP injection) (Fig. $1 A$ ). The decrease in the mechanical threshold peaked at $5 \mathrm{~min}$ and lasted for at least $2 \mathrm{hr}$ after injection of $\alpha \beta$ meATP. All of the rats before intraplantar injections did not respond to the filaments used here (0.4-15.1 gm), and the mechanical threshold for PBS-treated rats did not change significantly during behavioral observation (Fig. $1 A$ ). At $5 \mathrm{~min}$ after injection of $\alpha \beta$ meATP $(100 \mathrm{nmol})$, a marked increase in the frequency of the paw withdrawal response to von Frey filaments (2.0 and $5.0 \mathrm{gm})$ was observed only in the injected hindpaw $(p<$ 0.01 , significantly different from the frequency in contralateral hindpaw), and not in noninjected hindpaw; these filaments did not produce withdrawal response in normal rats (Fig. $1 B)$. These results indicate that application of $\alpha \beta$ meATP into the plantar surface can produce mechanical allodynia. Furthermore, the $\alpha \beta$ meATP-induced mechanical allodynia was produced in a dosedependent fashion (Fig. 1D) and was significantly blocked by intraplantar pretreatment with the $\mathrm{P} 2$ receptor antagonist 

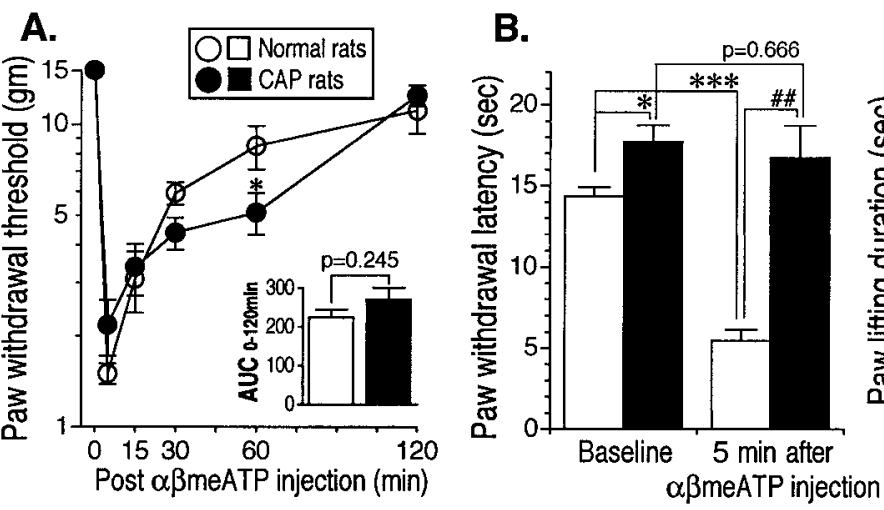

PPADS (30 and $100 \mathrm{nmol})(p<0.01$, significantly different from the AUC of threshold in PBS-pretreated rats) (Fig. 1C), indicating the mediation of $\mathrm{P} 2 \mathrm{X}$ receptors at the injection site. Pretreatment with PPADS did not significantly affect the paw withdrawal threshold ( $30 \mathrm{nmol}, 15.1 \pm 0 \mathrm{gm} ; 100 \mathrm{nmol}, 13.8 \pm 1.2 \mathrm{gm})$. The mechanical allodynia could also be produced by an endogenous agonist for P2X receptors, ATP (100 and $1000 \mathrm{nmol})(p<0.01$, significantly different from the AUC of threshold in PBS-treated rats) (Fig. $1 D$ ), although the dose-response curve for ATP was shifted to the right compared with that for $\alpha \beta$ meATP. This appears to reflect the rapid degradation of ATP by extracellular ectonucleotidases. Intraplantar injection with adenosine (1000 nmol) did not affect the paw withdrawal threshold for mechanical stimulus (Fig. 1D).

Systemic administration of capsaicin $(50 \mathrm{mg} / \mathrm{kg})$ to neonatal rats has been known to selectively destroy the capsaicin-sensitive neurons. In agreement with a previous study (Nagy and van der Kooy, 1983), the capsaicin-treated rats used here also exhibited a significant increase in basal paw withdrawal latency to heat $(p<$ 0.05 , significantly different from latency in normal rats) (Fig. 2B). Thus, we used this tool to examine the involvement of capsaicinsensitive primary afferent neurons in three behaviors induced by $\alpha \beta$ meATP. As shown in Figure $2 A$, an intraplantar injection of $\alpha \beta$ meATP $(100 \mathrm{nmol})$ produced a pronounced mechanical allodynia in both normal control and neonatal capsaicin-treated rats. In contrast, the thermal hyperalgesia (the decrease in the paw withdrawal latency to heat) (Fig. $2 B$ ) and nocifensive behavior (the paw-lifting behavior) (Fig. $2 C$ ) caused by an intraplantar injection of $\alpha \beta$ meATP (100 nmol) seen in normal rats disappeared in capsaicin-treated rats (Fig. 2, $B, C$ ).

\section{Slowly desensitizing P2X-mediated current persists after capsaicin treatment}

Consistent with our previous study (Ueno et al., 1999), the two kinetically distinct types of $\alpha \beta$ meATP $(100 \mu \mathrm{M})$-induced inward currents were detected in acute isolated rat DRG neurons: one is a rapid desensitizing current (Fig. $3 A$ ) and the other is a slow desensitizing current (Fig. $3 B$ ). The $\alpha \beta$ meATP-induced rapid desensitizing current was observed in $45 \%$ of normal rat DRG neurons tested that were mainly small and medium-sized in diameter $(\sim 22-30 \mu \mathrm{m})$ (Fig. $3 C$ ), whereas the $\alpha \beta$ meATPinduced slow desensitizing current was observed in $25 \%$ of DRG neurons tested that were mainly medium-sized in diameter ( $\sim 30-37 \mu \mathrm{m})$ (Fig. 3D). The other $30 \%$ of neurons did not respond to $\alpha \beta$ meATP $(100 \mu \mathrm{M})$. In DRG neurons from capsaicintreated rats, the percentage of cells that responded to $\alpha \beta$ meATP $(100 \mu \mathrm{M})$ with rapid desensitizing current in normal rats was dramatically decreased by $80 \%$ (from 45.5 to $9.6 \%$ ) ( $p<0.001$, significantly different from the percentage in normal rats) (Fig. $3 E$ ), and the current density of the rapid desensitization type of current was significantly decreased $(p<0.01$, significantly differ-

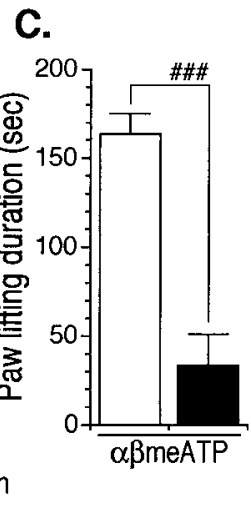

Figure 2. The $\alpha \beta$ meATP (100 nmol)-induced mechanical allodynia $(A)$ was almost unchanged in neonatal capsaicin-treated $(C A P)$ rats, whereas thermal hyperalgesia $(B)$ and nocifensive behavior $(C)$ disappeared in $C A P$ rats. $A$, Mean \pm SEM paw withdrawal threshold (in grams) for von Frey filaments $\left({ }^{*} p<0.05\right.$ by the Mann-Whitney $U$ test, compared with normal rats). Inset, Mean \pm SEM AUC at 0-120 min after injection. $B$, Mean \pm SEM paw withdrawal latency (sec) to heat stimulus 0 and 5 min after injection $\left[{ }^{*} p<0.05\right.$ (compared with normal rats), ${ }^{* * *} p<$ 0.001 , (compared with $\alpha \beta$ meATP-treated rats), and $\# \# p<0.01$ (compared with $C A P$ rats) by the Student's $t$ test or the Mann-Whitney $U$ test]. $C$, Mean \pm SEM paw-lifting duration (in seconds) during the first 4 min after injection (\#\#\# $p<0.001$ by the Student's $t$ test, compared with normal rats). Each point and column represents the mean \pm SEM of six rats.
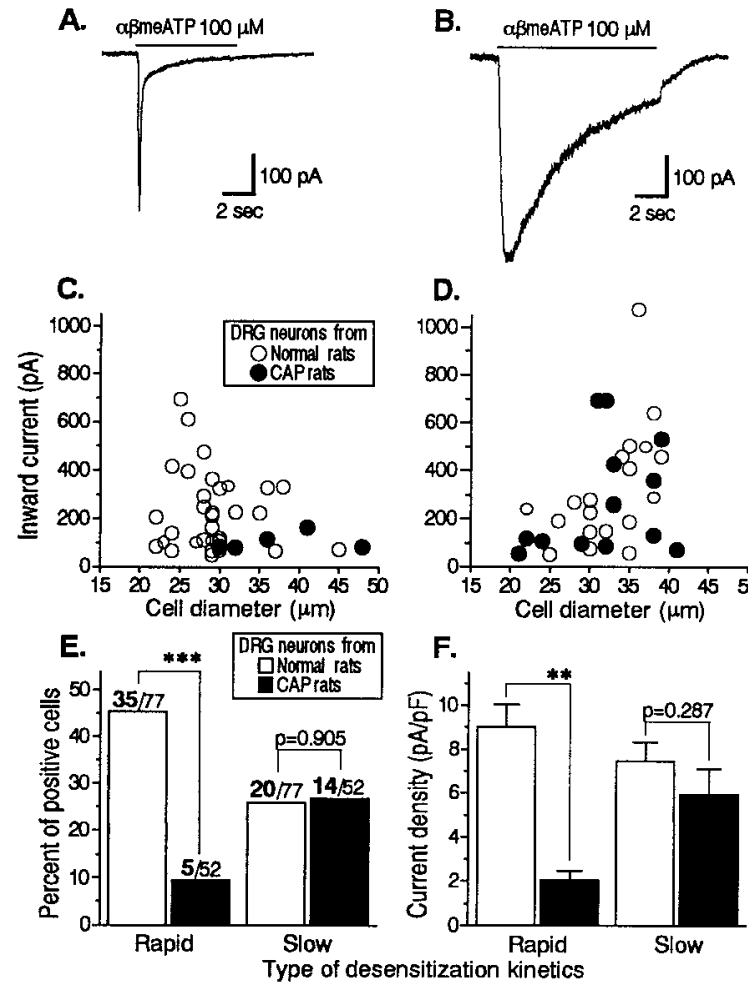

Figure 3. The DRG neurons that responded to $\alpha \beta \operatorname{meATP}(100 \mu \mathrm{M})$ with rapid desensitizing inward current disappeared in neonatal capsaicintreated $(C A P)$ rats, whereas those DRG neurons that responded with slow desensitizing current remained. $A, B$, Examples of typical $\alpha \beta$ meATP $(100 \mu \mathrm{M})$-evoked inward currents with rapid $(A)$ and slow $(B)$ desensitization in acute isolated DRG neurons from adult normal rats. $C, D$, Distribution of DRG neurons that responded to $\alpha \beta$ meATP $(100 \mu \mathrm{M})$ with rapid $(C)$ and slow $(D)$ desensitizing currents. DRG neurons were isolated from normal and $C A P$ rats. $E$, Percentage of positive DRG neurons that responded to $\alpha \beta$ meATP $(100 \mu \mathrm{M})$ in normal and $C A P$ rats $(* * * p<$ 0.001 by $\chi^{2}$ test, compared with normal rats). Values above columns indicate the number of responding cells per number of cells tested for each group. $F$, Mean \pm SEM current densities of the $\alpha \beta$ meATP $(100$ $\mu \mathrm{M})$-evoked inward currents with rapid and slow desensitization $(* * p<$ 0.01 by the Student's $t$ test, compared with normal rats).

ent from the current density in normal rats) (Fig. $3 F$ ). It seems that the relatively large-sized DRG neurons that have the low current density were resistant to capsaicin treatment (Fig. 3C). Conversely, there was no difference in the percentage of neurons that responded to $\alpha \beta$ meATP $(100 \mu \mathrm{M})$ with slow desensitizing current (from 26 to $26.9 \%$ ) (Fig. 3E), and the current density was not changed in capsaicin-treated rats compared with normal rats (Fig. $3 F$ ). 


\section{DISCUSSION}

In the present study, we have found three new and important aspects concerning the role of the ATP-P2X receptor system in signal transduction of pain, by using behavioral and electrophysiological approaches. One is that, in addition to previously described thermal hyperalgesia and nocifensive behavior (BlandWard and Humphrey, 1997; Hamilton et al., 1999), we found that a novel behavioral phenotype, mechanical allodynia, could be induced by local application of $\alpha \beta$ meATP into the plantar surface of the hindpaw. The intensity of mechanical allodynia caused by $\alpha \beta$ meATP is almost similar to that caused by intraplantar injection of inflammatory agents (carrageenan or complete Freund's adjuvant) (Nichols et al., 1999) and by an incision of the plantar surface (model of surgical pain) (Brennan et al., 1996). The $\alpha \beta$ meATP-induced mechanical allodynia appears to be a specific response mediated through the PPADS-sensitive $\mathrm{P} 2 \mathrm{X}$ receptors located at a peripheral injection site, because the mechanical allodynia is blocked by pretreatment with PPADS into the plantar surface; in addition, an intraplantar injection of endogenous P1 agonist adenosine failed to mimic the mechanical allodynia. Furthermore, the mechanical allodynia could also be produced by the endogenous agonist for $\mathrm{P} 2 \mathrm{X}$ receptors, ATP. These data suggest that under certain pathological situations after tissue injury, endogenous ATP, either released or leaked, could act on peripheral $\mathrm{P} 2 \mathrm{X}$ receptors and lead to the induction of mechanical allodynia. In the present study, relatively high doses of $\alpha \beta$ meATP and ATP were required to produce a clear mechanical allodynia. However, a large amount of ATP is present within the cytoplasm, which would leak out when cells are damaged. Thus, neurons would have a chance to be exposed to a relatively high concentration of ATP. Alternatively, it has been shown recently that the function of $\mathrm{P} 2 \mathrm{X}$ receptors is enhanced by various substrates and extracellular conditions generated during pathological situations, such as neuropeptides, arachidonic acid, and pH (Stoop et al., 1997; Wildman et al., 1997). Enhancement of the P2X receptormediated response has also been observed in an in vivo experiment by Hamilton et al. (1999) showing that the dose of $\alpha \beta$ meATP to produce significant nocifensive behavior is $\sim 100$ fold lower in an inflamed hindpaw than in a normal hindpaw. Under pathophysiological conditions, it is possible that the ability of ATP to produce mechanical allodynia may be enhanced, and that even a low ATP concentration could also produce a clear mechanical allodynia.

Our study and the studies of others (Bland-Ward and Humphrey, 1997; Hamilton et al., 1999) have clearly shown that activation of the peripheral $\mathrm{P} 2 \mathrm{X}$ receptors in the rat hindpaw leads to the induction of the three different behavioral phenotypes (i.e., nocifensive behavior, thermal hyperalgesia, and newly characterized mechanical allodynia). However, it is not known whether these behaviors are evoked through a common pathway from the periphery to the spinal cord. The second notable finding in the present study is the evidence that the mechanical allodynia and other behaviors (thermal hyperalgesia and nocifensive behavior) are signaled by distinct primary afferent neurons, by using neonatal capsaicin-treated rats in which capsaicin-sensitive neurons had been destroyed (Jancsó et al., 1977; Nagy et al., 1983; Guo et al., 1999). We found that the $\alpha \beta$ meATP-induced thermal hyperalgesia and nocifensive behavior are mediated through the capsaicin-sensitive fibers, and mechanical allodynia is mediated through the capsaicin-insensitive fibers. This finding indicates that not all $\mathrm{P} 2 \mathrm{X}$ receptor-mediated pain behaviors involve the capsaicin-sensitive primary afferent fibers. It is also conceivable that $\alpha \beta$ meATP, like bradykinin (Levine et al., 1986) or nerve growth factor (NGF) (Lewin et al., 1994), may indirectly activate primary afferent neurons via the release of other mediators from sympathetic postganglionic neuronal terminals or mast cells. However, the involvement of these sites in the $\alpha \beta$ meATP- induced behaviors may be negligible, because unlike bradykinin and NGF (Levine et al., 1986; Lewin et al., 1994), neither the sympathetic postganglionic neuron-selective neurotoxin 6-hydroxydopamine nor a potent mast cell degranulator compound 48/80 could modify these behaviors (our unpublished data). Therefore, these observations lead to a suggestion that the $\alpha \beta$ meATP-induced behavioral responses are mediated through direct activation of $\mathrm{P} 2 \mathrm{X}$ receptors located on peripheral terminals of sensory neurons rather than through indirect activation via sympathetic postganglionic neurons or mast cells. This possibility is also supported by the rapid onset of these behavioral responses (Bland-Ward and Humphrey, 1997; Hamilton et al., 1999; current study) and by the rapid excitation of primary afferent fibers caused by $\alpha \beta$ meATP and ATP (Dowd et al., 1998).

The behavioral data obtained from the present study are of particular interest, because we have demonstrated previously that the two types of ATP-evoked responses are classified by capsaicin sensitivity; i.e., capsaicin-sensitive DRG neurons have a rapid desensitizing current, and capsaicin-insensitive, medium-sized DRG neurons have a slow desensitizing current (Ueno et al., 1999). In agreement with this study, we determined in this study that DRG neurons that responded to $\alpha \beta$ meATP with a rapid desensitizing inward current selectively disappeared in capsaicintreated rats, whereas DRG neurons that responded to $\alpha \beta$ meATP with a slow desensitization were not affected. The third finding that, similar to the pain-related behaviors, the two types of ATP-evoked responses were clearly classified by capsaicin sensitivity suggests that the $\alpha \beta$ meATP-induced allodynic and hyperalgesic behaviors would be mediated by distinct $\mathrm{P} 2 \mathrm{X}$ receptors. We have revealed previously that the $\alpha \beta$ meATP-evoked inward currents with rapid and slow desensitization in rat DRG neurons closely resemble those obtained from homomeric $\mathrm{P} 2 \mathrm{X}_{3}$ receptors and heteromeric $\mathrm{P} 2 \mathrm{X}_{2 / 3}\left(\mathrm{P} 2 \mathrm{X}_{2}\right.$ and $\left.\mathrm{P} 2 \mathrm{X}_{3}\right)$ receptors, respectively (Ueno et al., 1998, 1999). Immunocytochemical studies have shown that the $\mathrm{P} 2 \mathrm{X}_{3}$ receptor subtype is observed mainly in capsaicin-sensitive DRG neurons (Vulchanova et al., 1998) and peripheral nerve endings (Cook et al., 1997; Vulchanova et al., 1998). Furthermore, a subpopulation of DRG neurons possesses both $\mathrm{P} 2 \mathrm{X}_{2}$ and $\mathrm{P} 2 \mathrm{X}_{3}$ receptors (Vulchanova et al., 1997). We have also found previously that $\mathrm{mRNAs}$ of $\mathrm{P} 2 \mathrm{X}_{2}$ and $\mathrm{P} 2 \mathrm{X}_{3}$ receptors are detected in medium-sized rat DRG neurons (Ueno et al., 1999). Taken together with our present results, these findings indicate that the responses mediated by homomeric $\mathrm{P} 2 \mathrm{X}_{3}$ and heteromeric $\mathrm{P} 2 \mathrm{X}_{2 / 3}$ receptors are possibly involved in the induction of thermal hyperalgesia and nocifensive behavior and in the induction of mechanical allodynia, respectively. However, in addition to $\mathrm{P} 2 \mathrm{X}_{2 / 3}$ receptor, other heteromeric $\mathrm{P} 2 \mathrm{X}$ receptors sensitive to $\alpha \beta$ meATP and PPADS have also been reported (Lê et al., 1999). Furthermore, we cannot completely exclude the possibility that the $\mathrm{P} 2 \mathrm{X}_{3}$ receptor, which survived after capsaicin treatment, may be sufficient to generate the mechanical allodynia. Thus, the discovery of new selective antagonists or the development of knockout animals for each P2X receptor subtype is awaited to clarify our hypothesis.

It has been postulated that ATP and P2X receptors play a role in various pain states (for review, see Burnstock and Wood, 1996). For example, a large amount of ATP released from the cytoplasm of damaged cells into the extracellular space may be involved in the induction of pain caused by tissue injury such as surgery. Recently, we have obtained evidence that the signaling pathways mediated by the $\mathrm{P} 2 \mathrm{X}$ receptors play a role in the induction of mechanical allodynia in a rat model of surgical pain (our unpublished observations). Furthermore, recent work has shown that an increase in the immunoreactivity for the $\mathrm{P} 2 \mathrm{X}_{3}$ receptor subtype in DRG neurons is observed in the rat model of neuropathic pain (Novakovic et al., 1999). Therefore, the mechanisms underlying $\mathrm{P} 2 \mathrm{X}$ receptor-mediated mechanical allodynia may be one of the 
determining factors of the mechanical allodynia in these painful states. Elucidation of this pathway may lead to the discovery of a new class of compounds that suppress mechanical allodynia in pathological pain.

\section{REFERENCES}

Bland-Ward PA, Humphrey PPA (1997) Acute nociception mediated by hindpaw $\mathrm{P} 2 \mathrm{X}$ receptor activation in the rat. $\mathrm{Br} \mathrm{J}$ Pharmacol 122:365-371.

Brennan TJ, Vandermeulen EP, Gebhart GF (1996) Characterization of a rat model of incision pain. Pain 64:493-501.

Burnstock G, Wood JN (1996) Purinergic receptors: their role in nociception and primary afferent neurotransmission. Curr Opin Neurobiol 6:526-532.

Caterina MJ, Schumacher MA, Tominaga M, Rosen TA, Levine JD, Julius D (1997) The capsaicin receptor: a heat-activated ion channel in the pain pathway. Nature 389:816-824.

Chaplan SR, Bach FW, Pogrel JW, Chung JM, Yaksh TL (1994) Quantitative assessment of tactile allodynia in the rat paw. J Neurosci Methods 53:55-63.

Chen CC, Akopian AN, Sivilotti L, Colquhoun D, Burnstock G, Wood JN (1995) A P2X purinoceptor expressed by a subset of sensory neurons. Nature 377:428-431.

Collo G, North RA, Kawashima E, Merlo-Pich E, Neidhart S, Surprenant A, Buell G (1996) Cloning of $\mathrm{P}_{2} \mathrm{X}_{5}$ and $\mathrm{P} 2 \mathrm{X}_{6}$ receptors and the distribution and properties of an extended family of ATP-gated ion channels. J Neurosci 16:2495-2507.

Cook SP, Vulchanova L, Hargreaves KM, Elde R, McCleskey EW (1997) Distinct ATP receptors on pain-sensing and stretch-sensing neurons. Nature 387:505-508.

Dowd E, McQueen DS, Chessell IP, Humphrey PPA (1998) P2X receptor-mediated excitation of nociceptive afferents in the normal and arthritic rat knee joint. Br J Pharmacol 125:341-346.

Guo A, Vulchanova L, Wang J, Li X, Elde R (1999) Immunocytochemical localization of the vanilloid receptor 1 (VR1): relationship to neuropeptides, the $\mathrm{P} 2 \mathrm{X}_{3}$ purinoceptor, and IB4 binding sites. Eur J Neurosci 11:946-958

Hamill OP, Marty A, Neher E, Sakmann B, Sigworth FJ (1981) Improved patch-clamp techniques for high-resolution current recording from cells and cell-free membrane patches. Pflügers Arch 391:85-100.

Hamilton SG, Wade A, McMahon SB (1999) The effects of inflammation and inflammatory mediators on nociceptive behaviour induced by ATP analogues in the rat. Br J Pharmacol 126:326-332.

Jancsó G, Kiraly E, Jancsó-Gábor A (1977) Pharmacologically induced selective degeneration of chemosensitive primary sensory neurones. Nature 270:741-743.

Lê K-T, Babinski K, Séguéla P (1999) Central P2X ${ }_{4}$ and P2X $\mathrm{X}_{6}$ channel subunits coassemble into a novel heteromeric ATP receptor. J Neurosci 18:7152-7159.

Levine JD, Taiwo YO, Collins SD, Tam JK (1986) Noradrenaline hyperalgesia is mediated through interaction with sympathetic postganglionic neurone terminals rather than activation of primary afferent nociceptors. Nature 323:158-160.

Lewin GR, Rueff A, Mendell LM (1994) Peripheral and central mechanisms of NGF-induced hyperalgesia. Eur J Neurosci 6:1903-1912.

Lewis C, Neidhart S, Holy C, North RA, Buell G, Surprenant A (1995) Co-expression of $\mathrm{P} 2 \mathrm{X}_{2}$ and $\mathrm{P} 2 \mathrm{X}_{3}$ receptor subunits can account for ATP-gated currents in sensory neurons. Nature 377:432-435.

Nagy JI, van der Kooy D (1983) Effects of neonatal capsaicin treatment on nociceptive thresholds in the rat. J Neurosci 3:1145-1150.

Nagy JI, Iversen LL, Goedert M, Chapman D, Hunt SP (1983) Dosedependent effects of capsaicin on primary sensory neurons in the neonatal rat. J Neurosci 3:399-406.

Nichols ML, Allen BJ, Rogers SD, Ghilardi JR, Honore P, Luger NM, Finke MP, Li J, Lappi DA, Simone DA, Mantyh PW. (1999) Transmission of chronic nociception by spinal neurons expressing the substance P receptor. Science 286:1558-1561.

Novakovic SD, Kassotakis LC, Oglesby IB, Smith JA, Eglen RM, Ford AP, Hunter JC (1999) Immunocytochemical localization of $\mathrm{P}_{2 \times 3}$ purinoceptors in sensory neurons in naive rats and following neuropathic injury. Pain 80:273-282.

Ralevic V, Burnstock G (1998) Receptors for purines and pyrimidines. Pharmacol Rev 50:413-492.

Stoop R, Surprenant A, North RA (1997) Different sensitivities to pH of ATP-induced currents at four cloned P2X receptors. J Neurophysiol 78:1837-1840.

Ueno S, Koizumi S, Inoue K (1998) Characterization of $\mathrm{Ca}^{2+}$ influx through recombinant $\mathrm{P} 2 \mathrm{X}$ receptor in C6BU-1 cells. Br J Pharmacol 124:1484-1490.

Ueno S, Tsuda M, Iwanaga T, Inoue K (1999) Cell type-specific ATPactivated responses in rat dorsal root ganglion neurons. Br J Pharmacol 126:429-436.

Vulchanova L, Riedl MS, Shuster SJ, Buell G, Surprenant A, North RA, Elde R (1997) Immunohistochemical study of the P2X $\mathrm{X}_{2}$ and P2X receptor subunits in rat and monkey sensory neurons and their central terminals. Neuropharmacology 36:1229-1242.

Vulchanova L, Riedl MS, Shuster SJ, Stone LS, Hargreaves KM, Buell G, Surprenant A, North RA, Elde R (1998) P2X 3 is expressed by DRG neurons that terminate in inner lamina II. Eur J Neurosci 10:3470-3478.

Wildman SS, King BF, Burnstock G (1997) Potentiation of ATPresponses at a recombinant $\mathrm{P}_{2 \times 2}$ receptor by neurotransmitters and related substances. Br J Pharmacol 120:221-224.

Xiang Z, Bo X, Burnstock G (1998) Localization of ATP-gated P2X receptor immunoreactivity in rat sensory and sympathetic ganglia. Neurosci Lett 256:105-108. 